\title{
ARTE COMO LUGAR DA MEMÓRIA
}

\author{
ART AS A MEMORY PLACE
}

\section{ARTE COMO LUGAR DE LA MEMORIA}

\section{Alecsandra Matias de Oliveira ${ }^{1}$}

\section{RESUMO:}

O presente estudo aborda as relações existentes entre história, memória e arte, registradas através de monumentos arquitetônicos na cidade de São Paulo. A história da arte e seus desdobramentos estéticos são considerados na análise, como referenciais metodológicos.

Palavras-chave: Arte; História; Memória; Monumentos; São Paulo.

\section{ABSTRACT:}

This study addresses the relationship among history, memory and art, registered through architectural monuments in the city of São Paulo. The history of art and its aesthetic developments are considered, in the analysis, as methodological referential.

Keywords: Art; History; Memory; Monuments; São Paulo.

\section{RESUMEN:}

Este estudio aborda las relaciones existentes entre la historia, la memoria y el arte, registradas por medio de monumentos arquitectónicos en la ciudad de São Paulo. La historia del arte y sus desdoblamientos estéticos son considerados en el análisis como marcos de referencia metodológicos.

Palabras-clave: Arte; Historia; Memoria; Monumentos; São Paulo.

\section{INTRODUÇÃO}

O processo da memória no homem faz intervir não só a ordenação de vestígios, mas também a releitura desses vestígios (APUD. CHANGEUX, LE GOFF, 2003, p. 420).

1 Doutora em Artes pela Universidade de São Paulo, USP (2008). Mestre em Ciências da Comunicação pela Universidade de São Paulo, USP (2003), Graduação em História pela Faculdade de Filosofia, Letras e Ciências Humanas (1995). Atualmente é especialista em cooperação e extensão universitária da Universidade de São Paulo, USP. Tem experiência na área de Artes, com ênfase em História da Arte, atuando principalmente nos seguintes temas: arte, história da arte, arte brasileira, história e crítica de arte.

R. Inter. Interdisc. INTERthesis, Florianópolis, v.6, n.2, p. 106-122, jul./dez. 2009 
A memória está presente em diversos campos do Saber e ações do Homem. Pode ser compreendida como a capacidade do indivíduo em conseguir conservar e retomar certas informações ou impressões do passado. Essa capacidade deve ser entendida como algo inserido à vida social. Para Le Goff, renomado historiador francês, a memória é um comportamento narrativo que tem em seu cerne a função social de comunicar a outras pessoas informações e impressões ocorridas no passado as quais não estão no presente em sua forma original (LE GOFF, 2003).

O século XXI inicia com uma discussão bastante expressiva no que toca à conceituação da memória, em face da rápida evolução tecnológica. Na perspectiva aberta pelas novas tecnologias, uma das principais alterações é a ampliação do próprio conceito de memória, que se torna cada vez mais disseminado no campo de estudo de diversas áreas do conhecimento: na Filosofia, por exemplo, com os escritos de Bérgson; na Literatura, com a narrativa de Marcel Proust e na Psicanálise, a partir das teorias freudianas. Acrescentem-se, os vários trabalhos em Antropologia e Psicologia Social que tratam, particularmente, sobre a memória coletiva. Observa-se, então, que ao estudo dos fenômenos mnemônicos é possível atribuir uma visão interdisciplinar.

$\mathrm{Na}$ pesquisa artística, as representações em torno da memória podem ser explícitas, revelando acontecimentos históricos ou mitológicos, como na arte grega, romana, cristã ou renascentista. Podem desvelar aspectos éticos, psicológicos e culturais, tal como no Romantismo. No início do século $X X$, as vanguardas têm no Surrealismo, as aproximações entre memória e sonhos; no Expressionismo registram-se sentimentos íntimos. Através dessas representações, a arte pode denunciar contradições sociais ou políticas e indicar sensações inerentes à condição humana, como na arte contemporânea, por exemplo.

Imersos nas redes mnemônicas, artistas e novas propostas estéticas têm fundamental papel na construção de seu tempo através de múltiplas linguagens. Alguns atingem significativo grau de especificidade no modo de construção desenvolvido, tornando-se, de certa forma, cronistas do cotidiano - uma expressão que somente pode ser compreendida através da reconstituição da memória do momento presente, na qual existe um tempo fragmentado diante da profusão de imagens, sons e sentidos integrantes da sociedade contemporânea.

No presente exercício de reflexão sobre a memória e suas aplicações artísticas, surgem as seguintes questões: através da arte resgatam-se memórias e R. Inter. Interdisc. INTERthesis, Florianópolis, v.6, n.2, p. 106-122, jul./dez. 2009 
narrativas imersas na malha urbana? Ou ainda, registros artísticos, especialmente, monumentos podem construir um lugar de memórias, particularmente em grandes centros urbanos - como é o caso da cidade de São Paulo?

As relações entre arte e memória adquirem maior complexidade quando se pensa nas dimensões de uma cidade como São Paulo, em permanente ebulição econômica, social, cultural, política e artística - mesclada por diversas culturas vindas de várias partes do mundo (imigrantes italianos, espanhóis, japoneses, árabes, judeus, entre outros) e por migrantes de todas as regiões do país (mineiros, cearenses, baianos, paraibanos, goianos, entre outros). A cidade se transforma em um tecido de 60 mil ruas e avenidas, mais de 3 milhões de prédios, casas, indústrias e escritórios, 5 milhões de veículos e 10 milhões de habitantes que dispõem de memórias individuais e coletivas expressas em diversas manifestações artísticas diariamente.

Os fatos históricos que desvelam as memórias de São Paulo - e que tornam a cidade "um lugar" - estão registrados em ruas, avenidas, praças e outros logradouros públicos. Muitas vezes o espírito cívico motivou a construção desses monumentos, porém, é o senso estético que predomina em sua manufatura. Outras vezes, as peças perdem seus valores históricos e estéticos intrínsecos, tornando-se "invisíveis" ao público passante - são pequenos enigmas que cabe ao pesquisador tornar compreensível.

\section{DOCUMENTOS E MONUMENTOS}

Os grupos sociais, antes da escrita, partilham suas experiências, transmitindo conhecimento oralmente, de geração para geração, sob a forma de mitos, lendas e narrativas contadas ou cantadas. O saber somente era guardado na mente humana (TOMAZ, 1992). Até o advento da escrita, a memória extirparia-se com a morte do indivíduo. O registro escrito rompe a barreira física, propiciando a conservação de fragmentos do conhecimento de um modo externo ao corpo. A escrita torna-se uma forma de transformação da memória do grupo - permanece aquela que consegue transpor a fronteira do tempo, ou seja, a que está registrada.

O registro mnemônico permite o seu desenvolvimento em dois tipos de materiais: o documento escrito (escolha do historiador) e a celebração através de um monumento comemorativo (herança do passado). Documentum deriva de

R. Inter. Interdisc. INTERthesis, Florianópolis, v.6, n.2, p. 106-122, jul./dez. 2009 
docere, "ensinar", com o tempo, o termo evolui para "prova" e é costumeiramente utilizado no vocabulário legislativo (LE GOFF, 2003). Monumentum remete à raiz indo-européia men que exprime uma das funções essenciais do espírito (mens), a memória (memini). O verbo monere significa "fazer recordar", "avisar", "iluminar", "instruir". O monumentum é um sinal do passado - tudo aquilo que pode evocar o passado e perpetuar a recordação (LE GOFF, 2003).

Os monumentos comemorativos são múltiplos em diversas partes do mundo. O monumento pode configurar-se como obra comemorativa de arquitetura ou escultura (arco do triunfo, coluna, troféu e pórtico) ou, ainda, de caráter funerário destinado a conservar a memória de uma pessoa no domínio da morte (pirâmides, túmulos e mausoléus). No Oriente antigo, por exemplo, os obeliscos e as estelas desempenham papel especial na perpetuação dos grandes triunfos, através de representações figuradas acompanhadas por inscrições que permitem transmitir às gerações futuras aquelas vitórias. Para Le Goff, esses monumentos são "verdadeiros arquivos de pedra" que acumulam, além da função de arquivo propriamente dito, a de "peças publicitárias" duradouras (LE GOFF, 2003).

Nesses monumentos, a marca principal é o esforço em manter a comemoração e a lembrança por intermédio de imagens e inscrições que, geralmente, encerram uma narrativa dos eventos gloriosos. Na transição entre a oralidade e o registro escrito (através de monumentos ou documentos) ocorre a "domesticação do pensamento selvagem" (LE GOFF, 2003, p.420). O registro da memória permite o partilhar de narrativas caras à sociedade que o constitui. Através dos registros, os indivíduos normatizam o convívio social e, de certo modo, perpetuam a tradição. A memória registrada é uma exigência coletiva nas sociedades históricas.

Talvez, a reconstrução temporal dos monumentos advenha do conceito de "rastro" - tão utilizado em reflexões sobre a memória. A história-registro, por muitos anos, considera que um esforço de lembrança (através, por exemplo, de um documento ou monumento) poderia ressuscitar o passado, transformando o presente em uma "amálgama" - uma reconstrução e uma releitura do que passa, a partir da inserção do indivíduo na coletividade e em momentos presentes sucessivos. Por essa razão, se dá a insistente interpretação sobre os "vestígios" de objetos e lembranças de realidades vivenciadas. As "pistas" e "índices" provenientes 
de imagens verbais e não-verbais, especialmente as registradas, permitem, pelos fragmentos, uma busca lógica e elucidativa em determinado tempo e espaço.

Rastros, vestígios, pistas e índices são termos sinônimos que autorizam, por um trabalho de indução permeado pela intuição e pela imaginação, concluir a existência de acontecimentos que se encontram obscurecidos, porém, relacionados a circunstâncias conhecidas. O obscurecimento das lembranças está intimamente vinculado à memória, ou seja, o ser humano está naturalmente sujeito à lei do esquecimento e vive com este em eterna luta, pois necessita combatê-lo e, simultaneamente, contar com ele. Documentos e monumentos são instrumentos de luta contra o esquecimento, porque introjetam um significado simbólico intimamente ligado à evocação de memórias. Porém, os documentos e monumentos privilegiam certas memórias em detrimento de outras, ou seja, constituem o jogo memória versus esquecimento.

Nesse processo, o ato mnemônico, enquanto comportamento narrativo, permeado pelas tecnologias, atribui às lembranças configurações maquínicas que, em última instância, manipulam a memória coletiva. Assinala-se, nesse ponto, que uma das grandes problemáticas da contemporaneidade reside no acúmulo de memória e seu conseqüente esquecimento. A atual "cultura da memória" parece sofrer de amnésia, devido ao acesso maquínico (da imprensa à televisão, passando por CD-roms e internet) que gera uma "falta de vontade de lembrar" que, por sua vez, acarreta perda da consciência histórica (HUYSSEN, 2000). Outro dado significativo contemporâneo reside no grande número de memórias comercializadas em massa que são rapidamente consumidas e, por essa razão, são de mais fácil esquecimento - fato não tão comum à memória vivida.

É perceptível, então, que a memória também depende de mecanismos de seleção e descarte, sendo vista como um sistema de esquecimento programado. $\mathrm{O}$ esquecimento é necessário para a sociedade e para o indivíduo. Sem o esquecimento a memória humana é impossível. Segundo Marc Augé: "É preciso saber esquecer para saborear o gosto do presente, do instante e da espera, mas a própria memória necessita do esquecimento: é preciso esquecer o passado recente para recobrar o passado remoto" (AUGÉ, 1998, p. 9).

A relação tempo e memória surge como ponto relevante na questão do esquecimento. O tempo apaga os rastros ou os transforma. A leitura de um documento ou monumento depende de sua relação com o presente. Segundo Augé,

R. Inter. Interdisc. INTERthesis, Florianópolis, v.6, n.2, p. 106-122, jul./dez. 2009 
"o esquecimento devolve o presente e se conjuga em todos os tempos: no futuro para viver o início; no presente, para viver o instante e no passado, para viver o retorno" (AUGÉ, 1998, p. 26). Impossível lembrar sem esquecer. Para lembrar determinados fatos é preciso esquecer outros - tal como a metáfora do jardineiro que poda as plantas para que floresçam com mais força. Como assinala, ainda, Augé: "Fazer o elogio do esquecimento não é vilipendiar a memória, e ainda menos ignorar a recordação, mas reconhecer o trabalho do esquecimento na primeira e assinalar sua presença na segunda" (AUGÉ, 1998, p. 19).

Le Goff, sobre a amnésia, pondera que esta não é uma perturbação somente do indivíduo, mas também a falta ou a perda, voluntária ou involuntária, da memória coletiva "pode determinar perturbações graves da identidade coletiva". Para o historiador:

Tornarem-se senhores da memória e do esquecimento é uma das grandes preocupações das classes, dos grupos, dos indivíduos que dominam as sociedades históricas. Os esquecimentos e os silêncios da história são reveladores desses mecanismos de manipulação da memória coletiva ( Le Goff, 2003, p. 425).

Considera-se, então, que a história se faz a partir de memórias e de esquecimentos, do mesmo modo que a produção artística se consolida ou se dissolve por esses elementos. Os repertórios, temas, linguagens, estilos e técnicas são recordações ou impressões que permanecem como o registro e o afeto de objetos exteriores em reação aos sentidos humanos. No estudo específico sobre os traços da memória na arte, os aspectos interdisciplinares precisam de maior aplicação, pois a própria natureza da arte exige essa qualificação da pesquisa. Monumentos e documentos são os registros que perpetuam a memória. Os registros artísticos mostram-se como diferenciais nessa busca em reconstituir o passado. Os monumentos artísticos encontram-se carregados de historicidade e, principalmente, trazem uma forte áurea simbólica capaz de unir a comunidade na qual estão imersos. Nesse sentido, a reflexão direcionada a partir das relações da memória e da história torna-se um importante subsídio, na tarefa de elucidar algumas questões relativas à interação entre arte e memória.

O embasamento histórico dos fenômenos da memória na arte aponta caminhos expressivos para a leitura dos monumentos arquitetônicos de São Paulo, particularmente, àqueles que possuem estrita relação com memórias consideradas fundantes da cidade, como por exemplo: o índio, os bandeirantes, a independência, 
a industrialização e os imigrantes. O que, verdadeiramente, é registrado nos monumentos: memórias ou a história de São Paulo?

\section{CONSTRUINDO UM LUGAR}

$\mathrm{Na}$ contemporaneidade, o fenômeno da globalização, progressivamente, comprime o "espaço/tempo", encurtando distâncias e acelerando os movimentos da vida. O senso específico de lugar, de casa, de lar, assim como sua idéia de tempo, inclui as tradições e narrativas que unem o passado e o presente. Conectam o indivíduo à sua história. A globalização e a rapidez da informação e da produção provocam uma mudança na relação espaço/tempo - uma destruição do espaço pelo tempo (CANTON, 2008).

Nessa nova configuração, a promessa de uma globalização econômica e social apresenta suas limitações, porque permite a uma minoria os confortos desta condição e impõe a maioria à exclusão. Para essa minoria, os possíveis "agora" se desdobram em infinitas realidades dispersas. O desejo pode estar em todos os lugares e em todos os tempos. Em grandes cidades, como por exemplo, São Paulo, essa situação desenraiza o indivíduo, tornando-o "homeless" - um "sem casa", destituído do sentimento de "em casa"; uma ausência de familiaridade com o mundo; certos modos de ser; sentidos compartilhados, crenças: a globalização impele o indivíduo à diáspora (à procura por uma identidade ou ainda à busca por memórias partilhadas) (VILACA, 1999).

É a perda das certezas. A identidade somente se torna uma questão quando algo que se supõe como fixo, coerente e estável é deslocado pela experiência da dúvida e da incerteza (CANTON, 2008). Já não se absolutiza questões referentes aos agrupamentos, tais como: gênero, classe social, etnia, nacionalidade ou sistema social. A própria noção unificada e estável de subjetividade passa por profundas alterações. O sujeito apresenta maior mobilidade. A noção de indivíduo, assim como a de memória, influencia-se e dirigi-se de acordo com as interações deste com outros indivíduos e instituições. Assim, o sujeito não é apenas um, mas possui diversas gradações que se modificam de acordo com o tipo de relação que estabelece com seu entorno - suas memórias também terão a mesma mobilidade (POLLAK, 1992). É justamente o entorno habitado pelo sujeito que se altera a partir da globalização - a cidade contemporânea torna-se fraturada e transitiva. Por

R. Inter. Interdisc. INTERthesis, Florianópolis, v.6, n.2, p. 106-122, jul./dez. 2009 
conseqüência, o sujeito antes unificado está se tornando cada vez mais fragmentado e temporário, já que as bases sobre as quais ele constrói sua identidade não são mais previsíveis, mas, ao contrário, variáveis (POLLAK, 1992).

$\mathrm{Na}$ edificação do lugar contemporâneo, há uma estreita relação entre a memória e o sentimento de identidade (Idem). Nessa construção da identidade, há a unidade física, ou seja, o sentimento de ter fronteiras físicas, no caso do corpo da pessoa, ou fronteiras de pertencimento ao grupo, no caso de um coletivo; há a continuidade dentro do tempo, no sentido físico da palavra, mas também no sentido ético e psicológico (Idem). Desse modo, a memória é um elemento constituinte do sentimento de identidade, tanto individual como coletiva, na medida em que também é fator relevante do sentimento de continuidade e de coerência de uma pessoa ou de um grupo em sua reconstrução de si (HALL, 2005).

"O estabelecimento da identidade é um processo cultural e simbólico realizado a partir de diversos enraizamentos" (WEIL, 2001, p. 32). Esses enraizamentos se estabelecem a partir do contexto de tempo e de espaço, nos quais o indivíduo procura os elementos constituintes de sua identidade mutável. Os membros de um grupo particular como aqueles ligados por gênero, faixa etária, estrato social, etnias, religião, possuem uma extensa rede de articulações tanto na linguagem como nas crenças partilhadas de uma localidade (Idem). Dentro das linguagens possíveis, as artes visuais apresentam-se como campo aberto para o surgimento de diversos discursos, porque são capazes de espelhar as diferenças ocultas sob muitas outras - até mesmo em indivíduos com ancestralidade e história em comum. Com essas condicionantes, os indivíduos deslocam-se tão aceleradamente por espaços reais e virtuais que parecem estar sempre no mesmo lugar, sentindo o vazio de não chegar a lugar algum (HALL, 2005).

A globalização estabelece uma identidade homogênea do grupo privilegiado que têm acesso ao processo, uma vez que as possibilidades tecnológicas oferecem mensagens instantâneas e internacionalizadas (VILACA, 1999). O volume dessas mensagens homogeneizadas é avassalador o que provoca no indivíduo uma sensação de estranhamento, de distanciamento e de passividade. Na maioria das vezes, são mensagens sem mensageiros ou destinatários que deixam no indivíduo a sensação de perplexidade. É a criação de um mundo desabitado, no qual a última morada já está em vias de rompimento: o corpo. Considerado a referência estável da modernidade, o corpo é apresentado como o lugar do ser, da razão e da

R. Inter. Interdisc. INTERthesis, Florianópolis, v.6, n.2, p. 106-122, jul./dez. 2009 
consciência. Hoje, o corpo cede espaço à relativização da presença cyber corporal (CANTON, 2008).

Afinal, na contemporaneidade, o indivíduo está em algum lugar ou em lugar nenhum? A arte pode resgatar a sensação de lugar perdido (o sentimento de "em casa")? Existe nas artes visuais a criação de espaços plásticos e afetivos que contam e compartilham as memórias, a exemplo do que acontece com as obras de Proust na literatura? Em São Paulo, os sentimentos de desraizamento e de pertencimento são complementares. A cidade, considerada a maior da América Latina, é um conglomerado arquitetônico mesclado por pessoas vindas de diversos locais do Brasil e do mundo. O sentimento de "em casa" e de "homeless" apresentase fortemente nesse ambiente urbano. Embora, São Paulo proponha espaços (presenciais e virtuais) globalizados cotidianamente, sua população está longe de traços identitários homogeneizados.

A vocação cosmopolita da cidade advém do movimento de industrialização pós-1920. De lá para cá, a cidade mostra-se cada vez mais global. Simultaneamente, as "etnias" presentes na malha urbana têm, crescentemente, a preocupação de marcarem suas memórias em lugares específicos da cidade, erigindo (ou às vezes, destruindo) monumentos que evocam suas identidades. Essas intervenções são responsáveis pela construção de um lugar, no qual os indivíduos, concomitantemente, resgatam o registro de suas memórias (o sentimento de "em casa") e o apagamento delas (a sensação de "homeless" - "sem casa").

São Paulo, então, pode ser vista como um campo, onde as questões sobre os espaços, a arte e a memória estão emaranhadas. Recentes políticas públicas, revitalização de lugares e formas estabelecidas de arte pública lutam para a manutenção e renovação da memória coletiva urbana. O acelerado processo de integração global das cidades tem alterado radicalmente as condições e os princípios das intervenções - é importante ressaltar que esse é um movimento mundial (BRISSAC, 2007).

Grandes projetos de desenvolvimento e de criação de instituições culturais transnacionais estão ocasionando profundas reestruturações nas cidades, em escala global. Exigem novo repertório técnico e institucional; novas estratégias para a ação no espaço urbano e, uma readequação dos espaços voltados à conservação da memória. Entre as estratégias, emerge a tendência à implantação de megamuseus e exposições temáticas de itinerância internacional, que subordinam R. Inter. Interdisc. INTERthesis, Florianópolis, v.6, n.2, p. 106-122, jul./dez. 2009 
produção e percepção estética à lógica espacial cercada por imensos ambientes artificiais e cenografados (Idem). Esse tipo de monumentalidade disponibiliza a cidade e a arte ao espetáculo que, por vezes, não traz contribuições significativas para a maioria dos habitantes - alguns autores alertam que o fator exclusão pode pesar muito nessas propostas grandiosas.

Para Nelson Brissac, um dos organizadores do evento Arte/Cidade, a ação artística no ambiente urbano contemporâneo, portanto, necessita ser pautada mais por proposta de atuação fluída e discursiva do que fixa e dirigida. Deve ser moldada, num grau decisivo, pelas circunstâncias e condições de cada lugar específico (Idem). Envolvido na edificação de lugares, o artista não é um "criador de sociedades" e tampouco se tornar um espelho passivo da realidade. $O$ artista procura alterar a paisagem em volta, em alguns casos recupera espaços degradados e incentiva o debate sobre os problemas e questões sociais (Idem). Como membro da comunidade não se afasta das implicações relativas ao ambiente em que vive e, tampouco, evita as "responsabilidades éticas e políticas de sua inserção no espaço" ( BRISSAC, 2007).

Diante da idéia de monumento e aliando-se à idéia de arte pública, a concepção artística é capaz de transformar a consciência coletiva em relação aos movimentos de alteração dos espaços das cidades e semear um aspecto caro às ações estéticas interessadas em discutir o ambiente urbano: a dimensão de uma prática conectada aos processos de constituição de lugares. Nesse contexto, a sensação de "não-lugar", os espaços a-históricos e a perda do valor da memória que são fatores componentes do discurso globalizante são combatidos por pessoas (artistas e fruidores) que utilizam a arte pública para a construção de uma paisagem urbana plena de significações. O artista, como a figura de Jano (observando, simultaneamente, o passado e o futuro) pode interagir como um negociador entre as diversas memórias existentes na malha urbana; negociando com as identidades forjadas e, principalmente, atuando na construção de um lugar de memórias.

A intervenção do artista em espaços públicos é de fundamental relevância porque nesse contexto, o artista é o responsável por sensibilizar a população a atribuir memórias ou não a um determinado lugar. Algumas vezes, a missão de atribuição de memórias é, firmemente, abalada, configurando-se em casos tais como Tilted Arc (1981) de Richard Serra, em Nova York ou ainda a Pirâmide do arquiteto chinês I.M. Pei (1989) na área externa do Louvre - obras que não tiveram, em 
primeiro momento, receptividade pública positiva. Para o pleno êxito do engajamento da arte em espaços urbanos, o artista deve compreender que a cidade é um imenso palimpsesto, onde a evocação de imagens memoráveis serve-se dos momentos atuais e instaura uma nova forma de se relacionar com a obra, que, por sua vez, ganha sentido a partir das interferências contemporâneas - é uma constante e perene transformação de significados.

A idéia de cidade (coloque-se, nesse contexto, também as concepções de nação e comunidade) não é tão somente uma identidade política ou social, mas um sistema simbólico de produção de sentidos, de representação cultural e de discurso. A cidade surge, então, como produto da sobreposição de épocas, dos extratos temporais da memória. Difícil é a missão de recolher esses extratos e criar condições para sua adequação contemporânea.

Não são de manifestação imediata a lógica histórica e o controle de memória que se refletem na realidade urbana - o mais evidente é a desordem dos eventos herdados. Contudo, a cidade é o lugar da formação de um pensamento visual que permite encará-la no seu sentido museológico - a cidade-museu, segundo Katia Canton, torna-se depositária de poéticas visuais que evocam sentimentos de identificação e reconhecimento. $O$ fazer artístico contemporâneo reafirma essa concepção de cidade-museu, porque em meio a diversas possibilidades de uso de materiais, espaços e tempos, não se separa a rua e o museu (CANTON, 2008).

A discussão sobre a construção de lugares de memória em São Paulo tem continuidade quando se voltam às atenções para as "etnias" que mapeiam os espaços da metrópole paulistana. Os monumentos imersos na malha urbana servem como instrumentos de rememoração, porém, agregam os valores de construção do espaço a partir dos traços identitários da sociedade na qual estão inseridos. São Paulo, cidade de etnias múltiplas, possui memórias fundantes que são registradas nas ruas, alamedas, avenidas e praças da cidade (logradouros públicos da cidade).

\section{SÃO PAULO, UM LUGAR DE MEMÓRIAS}

Ao mergulhar nas relações entre cidade e arte, o acervo histórico dá conta de que as manifestações estéticas estão intimamente ligadas à vida urbana. A história da arte e suas relações com o meio urbano são quase tão antigas como a história do homem enquanto ser social. Na cidade de São Paulo, os monumentos erigidos na

R. Inter. Interdisc. INTERthesis, Florianópolis, v.6, n.2, p. 106-122, jul./dez. 2009 
malha urbana estão presentes desde o período colonial. A cidade, nascida ao redor do colégio jesuítico, cresce esquadrinhada por construções religiosas (São Francisco, São Bento, Carmo e do Colégio) e sobre o Espigão Central, o chamado Triângulo Histórico.

Os jesuítas fundam o Colégio de São Paulo de Piratininga, em 25 de janeiro de 1554, em uma colina alta e plana cercada por dois rios, o Tamanduateí e o Anhangabaú. Ao redor do Colégio as primeiras casas são erguidas e esse povoado torna-se vila em 1560, mas devido à distância do litoral, isolamento comercial e solo inadequado ao cultivo de produção de exportação, São Paulo ocupa uma posição secundária na colônia portuguesa. Cerca de 300 anos depois da fundação, seus 20 mil habitantes ainda moram em casas de pau-a-pique e taipa e a maioria dedica-se a hortas domésticas no Vale do Anhangabaú. Nesse lugar, o idioma oficial é o português, mas o que se escuta nas pequenas ruas é uma mescla de tupi e guarani.

Da herança indígena restam aldeamentos na periferia de São Paulo, em Parelheiros e aos pés do Pico do Jaraguá. Contudo, nas ruas e bairros da cidade, a memória dos primeiros habitantes se faz presente em nomes, tais como, Anhangabaú (água venenosa), Ibirapuera (madeira podre), Cambuci (pote ou espécie de árvore), Canindé (escuro), Ipiranga (água vermelha), Jabaquara (rocha ou buraco), Guainases (tribo indígena), Morumbi (morro ou colina alta), Pacaembu (ribeirão das pacas), Sapopemba (sapo-raiz ou pena-que-salta), Guapira (local onde inicia um vale), Miruna (gente escura), Tabantiguera (barro branco, saibro). Logradouros públicos da cidade reverenciam tribos indígenas e suas mulheres, como Bartira e as mulheres de Caramuru (Diogo Álvares), Moema (do tupi, nascer do dia) e Paraguaçu - e seus caciques Caiubi e Tibiriçá (TIRAPELI, 2007).

Já as memórias negras de São Paulo são lembranças dos negros que escravos, durante a colônia e o império, servem como mão-de-obra à economia do café. Os abolicionistas estão presentes nas avenidas Rebouças e Theodoro Sampaio e no Largo São Francisco com as recordações de Olavo Bilac, Castro Alves e outros que estudaram na Faculdade de Direito. Ou ainda, na Igreja de Nossa Senhora do Rosário dos Homens Pretos, no Largo do Paissandu, local onde se encontra a escultura Mãe Preta, de Júlio Guerra - local de manifestações religiosas e populares. Na Praça da Sé - marco zero da cidade - simbolicamente o escultor Rubem Valentim ergue um totem afro-reliogioso junto à catedral. E, por fim Emanoel 
Araujo cria o Museu Afro-Brasil, no Parque Ibirapuera, erigido às memórias negras da cidade.

Da gravura percussora de Débret no século XIX, passando pelas comemorações do Primeiro Centenário da Independência (1922), até o Quarto Centenário da fundação de São Paulo (1954), cria-se uma imagem idealizada dos bandeirantes, forjada, principalmente, por historiadores paulistas como Afonso Taunay, confirmada por artistas como o escultor italiano Luigi Brizzolara que dedica seus esforços na constituição de uma dimensão iconográfica. Acrescentem-se ao imaginário simbólico atribuído aos bandeirantes, os trabalhos emblemáticos de José Wasth Rodrigues e a concepção modernista de Victor Brecheret no Monumento às Bandeiras, considerado monumento-símbolo dos bandeirantes na capital.

Os monumentos que marcam os fatos do Império no século XIX se destacam em São Paulo a partir da emancipação política, em 7 de setembro de 1822. O "grito da Independência às margens do Ipiranga" motiva a implantação de um conjunto de monumentos que juntos relembram o fato histórico (o edifício-monumento, hoje o Museu Paulista; o jardim francês, atualmente, Parque da Independência e, o Monumento à Independência, de Ettore Ximenes). De todo o projeto inicial idealizado, o primeiro a ficar pronto é a tela Independência ou Morte, executada em Florença, Itália, em 1888. O Salão de Honra do atual Museu Paulista é projetado para abrigar essa obra que logo se torna um ícone da pintura nacional junto a outras de temas históricos.

Por volta do século XIX, São Paulo recebe suas primeiras edificações em tijolos, costume introduzido pelos ingleses com a construção de estações das estradas de ferro em 1865. A influência dos ingleses na cidade está associada à via férrea, ao bairro da Luz, a transações e empréstimos de bancos e aos reflexos das companhias estrangeiras no investimento da urbanização da cidade e à Companhia City. A partir da via férrea aparecem os novos bairros e instalações fabris instalados ao longo do eixo leste-oeste da cidade, pouco acima das várzeas alagáveis do Tietê.

$A$ virada do século $X I X$ para o século $X X$ marca, especialmente, a transição do regime imperial para o republicano. A cafeicultura altera a passagem do antigo arraial paulistano, de sertanista para a capital do café, com transformações dos lampiões a gás para a energia elétrica dos canadenses, novos bondes e os trilhos da estrada de ferro. Nessa mesma época, os imigrantes são atraídos pelo desejo de fortuna - promessa dos agentes de propaganda do governo brasileiro. A

R. Inter. Interdisc. INTERthesis, Florianópolis, v.6, n.2, p. 106-122, jul./dez. 2009 
implantação das estradas de ferro em 1867 e a ligação com o porto de Santos até o interior facilitam a chegada das levas de homens, mulheres e crianças até a Hospedaria dos Imigrantes (hoje, convertida em Museu do Imigrante) na capital.

A cidade de São Paulo sente a presença de portugueses, espanhóis, negros, povos germânicos, belgas, franceses, povos da Europa Central e Oriental, árabes, japoneses, coreanos e, por último a demanda de imigração de latino-americanos. Nesse processo imigratório, destacam-se os italianos que se tornam a grande massa de mão-de-obra, particularmente, operária e artesã da cidade em permanente construção. Dominam, a partir do emprego do estilo eclético, as técnicas de edificação de prédios e casarios que são realizados por artífices, professores e alunos do Liceu de Artes e Ofícios sob o comando do novo "construtor da cidade", Ramos de Azevedo.

Deslocando-se das lavouras de café à paisagem urbana paulistana, como operários das fábricas têxteis nos bairros de várzeas do Tamanduateí e à margem direita do Tietê, ao longo da via férrea, os imigrantes implantam vilas, ruas e edifícios monumentais. Juntos a Ramos de Azevedo e ao Liceu de Artes e Ofícios, principalmente, os italianos tornam-se os melhores e mais disputados arquitetos e construtores, substituindo as linhas francesas dos edifícios pelas neo-renascentistas italianas, como se vê no Edifício-Monumento do Ipiranga, no Teatro Municipal, no Edifício Martinelli, entre tantos outros. Os monumentos escultóricos dos artistas italianos também tomam conta das praças, como os realizados em homenagem a Carlos Gomes e ao compositor Giuseppe Verdi, além de Glória Imortal aos Fundadores de São Paulo e do Monumento à Independência no Ipiranga.

No movimento de industrialização e urbanização impelido à cidade de São Paulo, nas primeiras duas décadas do século $X X$, a expansão da cidade além dos centros (velho e novo) exige a implantação de mais viadutos e avenidas. O novo urbanismo conquista espaços: os primeiros quarteirões que ainda possuem casas coloniais são demolidos, e nas ruas e praças perfilam edifícios ecléticos. A velocidade dos carros e aviões, bem como as atividades esportivas e as noturnas invadem a cidade moderna. Em 1922, ocorre a Semana de Arte Moderna e a "Paulicéia Desvairada", expressão cunhada por Mário de Andrade, toma consciência de sua importância nas artes, na política e no desenvolvimento do restante do país. As características cosmopolitas da cidade motivam o Modernismo, abrigando numerosos artistas estrangeiros, principalmente oriundos da Itália, do Japão e do R. Inter. Interdisc. INTERthesis, Florianópolis, v.6, n.2, p. 106-122, jul./dez. 2009 
Leste Europeu. Estes artistas, cada qual à sua maneira, imprimem marcas pela cidade: o Futurismo dos italianos; o Expressionismo dos imigrantes da Europa Central, as tendências modernas parisienses e os imigrantes proletários das primeiras décadas do século XX revolucionam a arte e a cultura paulista, logo disseminadas por todo o país.

Hoje, a cidade tem em seus espaços diversos tempos e memórias - que são reverenciados e apagados cotidianamente. Os monumentos da cidade de São Paulo são carregados de historicidade - são marcas do desenvolvimento urbano permeado por diversas contribuições culturais. Esses movimentos, reminscências do passado que emergem no presente, transformam a cidade em "um lugar", no qual a coletividade se identifica. As sensações de pertencimento e estranhamento se alternam nessas construções identitárias.

\section{CONSIDERAÇÕES FINAIS}

A idéia de cidade não abarca somente uma identidade política ou social, mas um sistema simbólico de produção de sentidos, de representação cultural e, sobretudo, de memórias. A cidade contemporânea surge, então, como produto da sobreposição de épocas e de extratos culturais. A missão de recolher esses extratos é bastante desafiadora porque não se trata de manifestação imediata à lógica histórica e ao controle da realidade urbana. À primeira vista, o mais evidente é a desordem dos eventos herdados.

A sensação de desordem se dissipa quando se observa que a cidade se constitui como lugar de formação de identidades plurais que se mesclam e se sobrepõem. A possibilidade de expressão artística dinamiza um olhar mais acurado do transeunte no que diz respeito à organização do espaço toda vez que se estabelece um recorte do olhar sobre a paisagem. Esse transeunte passeia pela cidade num estado de coisas estético e faz algumas opções técnicas a partir dele. Entre a colônia e a grande metrópole, em São Paulo, o artista tem opções para compor esse metier. Essas opções decorrem de sua vivência cultural no espaço urbano. A cidade torna-se depositária de poéticas que evocam sentimentos de identificação e reconhecimento, somente um pensamento abrangente e plural permite encará-la no seu sentido polissêmico. As manifestações culturais contemporâneas reafirmam essa concepção de cidade, porque em meio a diversas

R. Inter. Interdisc. INTERthesis, Florianópolis, v.6, n.2, p. 106-122, jul./dez. 2009 
possibilidades de uso de materiais, espaços e tempos, não se separa a rua da cultura.

A cidade, através das intervenções culturais, é o espaço, por excelência, onde o homem se vê. É o lugar onde se reconhecem e se compartilham experiências. Espaço onde o "igual" e o "diferente" convivem, duelam e se complementam. No meio urbano, especialmente, em grandes metrópoles, as relações culturais se dão com maior intensidade porque os grupos sociais apresentam-se mais porosos e interagem cotidianamente. Nesse cenário, as artes visuais identificam, através de monumentos, os fatos e manifestações relevantes para aquela localidade.

Em resumo, na malha urbana, através de monumentos, registram-se fatos históricos e, sobretudo, memórias que constituem, acima de tudo, marcos espaciais presentes na cidade: a herança indígena, o legado dos bandeirantes, a independência, a industrialização, o movimento de imigração e, mais tarde, o de migração. A arte registra cada um desses acontecimentos históricos e imprime nos espaços urbanos, em diferentes níveis de historicidade, a batalha pela construção de um lugar e por uma identidade plural.

R. Inter. Interdisc. INTERthesis, Florianópolis, v.6, n.2, p. 106-122, jul./dez. 2009 


\section{REFERÊNCIAS}

BOSI, Eclea. Memória e Sociedade: Lembranças de Velhos. São Paulo: TA Queiroz/EDUSP, 1987.

BRESCIANI, Stella; NAXARA, Márcia (orgs.). Memória e (Res) Sentimento:

Indagações sobre uma Questão Sensível. Campinas: Editora da UNICAMP, 2004.

BRISSAC, Nelson. "Arte/Cidade - Um Balanço". Revista Ars - Programa de PósGraduação em Artes Visuais - ECA USP, São Paulo, ano 4, n.7, 2007.

CANTON, Kátia. "Tendências Contemporâneas: Questões sobre a Arte no Brasil e no Mundo Ocidental". In: AQUINO, Victor. Metáforas da Arte. São Paulo: MAC/PGEHA, 2008.

FISHER, Ernst. A Necessidade da Arte. Rio de Janeiro: Zahar Editora, 1959.

HALL, S. A Identidade Cultural na Pós-Modernidade. Rio de Janeiro: DP\&A, 2000.

LE GOFF, Jacques. História e Memória. São Paulo: Editora da Unicamp, 2003.

NORA, Pierre. "Entre Memória e História: a Problemática dos Lugares", Projeto História, n. 10, p. 7-28, dez. 1993.

OLIVEIRA, Alecsandra Matias. Poética da Memória: Maria Bonomi e Epopéia Paulista. São Paulo: Escola de Comunicações e Artes, 2008 (Tese de Doutorado).

POLLAK, Michael. "Memória e Identidade Social". Estudos Históricos, Rio de Janeiro, v. 5, n. 10, p. 200-212, 1992.

SANTOS, Milton. A Natureza do Espaço. São Paulo: Hucitec, 1999.

TIRAPELI, Percival. São Paulo: Artes e Etnias. São Paulo: Editora da UNESP/Imprensa Oficial, 2007.

WEIL, Simone. O Enraizamento. Bauru: EDUSC, 2001.

Artigo:

Recebido em: 21/07/2009

Aceito em: 18/09/2009

R. Inter. Interdisc. INTERthesis, Florianópolis, v.6, n.2, p. 106-122, jul./dez. 2009 